\section{SUPPORT THE AFRICAN STUDIES ASSOCIATION CHILDREN'S BOOK AWARD}

\section{Dear Friend of Africa,}

I am writing to enlist your support for the ASA Children's Book Award. The award was launched in 1991 by the African Studies Association to encourage the publication and use of accurate, balanced children's materials on Africa. The award focuses specifically on books published about Africa in the United States. Since 1991, our committee has awarded more than eighteen awards to outstanding authors and illustrators.

To increase public awareness about the award, we would like to develop a book seal and a website. The seal would be affixed to the covers of winning books, and the website would provide information about the award and award winning titles.

To launch and complete these worthy projects we need your financial support. As you are no doubt aware, most US school and public libraries have extremely poor materials on Africa. A book seal and a website will help educators, students and parents to quickly identify good materials and build better collections. If you care about the quality of children's collections on Africa, make a generous donation today. Collectively, we have the power to change the way America's children view Africa. Make your check payable to the ASA, and note "Children's Book Award Fund Donation" in the memo section. Please send donations to the ASA Executive Office, Rutgers University, 132 George Street, New Brunswick, NJ 08901-1400. Thank you for your support.

\section{Sincerely,}

Brenda Randolph, Chairperson

Children's Book Award Committee

brendar@umd5.umd.edu
NEWS FROM THE EDITORS OF THE AFRICAN STUDIES

More than two years ago, we took over from Mark Delancey as editors of the ASR, and while we have done a lot of work on the journal, there's not much in subscribers' hands to show for it. We want to tell you what's been happening.

So far, volume 42, numbers 1 (April 1998) and 2 (September 1998) and volume 42, number 3 (December 1998) have been printed and mailed to ASA members. All three numbers for volume 42 have been edited and are now in the hands of our production editor. After he completes formatting them, he will send them to the printer in Michigan, who sends each number directly to members. Our expectation is that members will have all three numbers of volume 42 mailed to them before the end of 1999. Then we will be caught up.

What's been the hold up?

When Mark Delancey edited the ASR, he sent his manuscripts to the ASA headquarters at Emory University, where the ASA staff completed the editing and formatting of each issue before it was sent to the printer. We became editors just at the time when the ASA Executive Office moved to Rutgers, and out of that move we were asked to take on the editing, formatting, and production for each number from volume 41 forward on our own. It took a while for us to assemble the know-how and the resources to meet these new expectations.

We sent a mailing to all ASA members, inviting respondents to identify how they could assist us in reviewing books and manuscripts. We heard from nearly half of the ASA members and created a reviewer database, which we and Book Review Editor Eugenia Herbert have been using successfully now for 15 months. After the ASA meetings of 1998, the ASA Executive Board andExecutive Office resolved all the outstanding production issues for us, and we have since then put together four numbers of the ASR. While the delays have been painful for you and us, we consider the wait almost worth it, especially in terms of how the ASR now looks, both in its cover design and the internal formatting of the contents.

Why does it take so long to get a manuscript in print?

Our biggest challenge right now is to shorten the time from submission to decision and on to printing, and the critical elements are finally in place to accomplish that. Here's 
how the process works:

1. We receive a manuscript. Office Manager Debbie Rotman opens mail three days a week and attends immediately to incoming manuscripts. If the author has not complied with the submission requirements (see below), she sends a letter or an e-mail stating that we cannot proceed with the review until the outstanding submission requirements are met.

2. For those manuscripts that meet the submission requirements we locate the manuscript's content by discipline(s), by topic(s), and by region. These three dimensions are used as criteria to search our reviewer database for peers who might be persuaded to review the manuscript. Typically we invite between five and eight reviewers to read each manuscript, and we send out a copy of the manuscript to the first five who accept the invitation. We ask for a comprehensive review to be submitted in two months' time, and we send e-mail reminders when that 60-day period comes to an end. As is normal for refered journals, we take several steps to keep the author's identity from the reviewers and vice versa.

3. Once we have received at least three detailed reviews, we decide to...

A. Accept with minor revisions.

B. Return to the author for revision, but with no promise of subsequent acceptance.

C. Outright rejection.

In all cases, we send the author copies of the reviewers' comments.

4. Assuming an acceptance, we provide the author with our own editorial suggestions, particularly if and when the external reviewers ask for contradictory changes. We invite the author to send in the revision within 60 days.

5. We ask the author to submit the final manuscript in both disk and paper formats. The copy on disk is then formatted according to our journal standard.

6. Then a new copy is printed from this disk, and both are sent to our editor, Ella Kusnetz, who not only rewrites poor sentence and paragraph constructions, but also copyedits the details.

7. Once Ella has finished her editing, the revised disk goes to Craig Malone of Malone Publishing, our production editor. He produces page proofs which we editors review.

8. Once we have made last minute changes to the page proofs, Craig assembles essays, book reviews, and ads into 224 pages of text and sends them directly and electronically to the printer.

9. The printer assembles the final typescript and sends the "blue line" back to Craig for any last minute changes. Changes at this stage are quite expensive, so we try to catch mistakes on earlier drafts.

10. The printer prints and mails the num-

ber to the ASA membership.

\section{The tough parts about being editors:}

1. Rejecting a manuscript. This is relatively easy when the reviewers are unanimous in the negative. It's harder when the reviewers are split. In such cases, we read the manuscript closely ourselves and often invite our faculty colleagues on the Five College African Studies Council to help us in coming to a judgment. Sometimes the external reviewers are split or mildly favorable, but we will still decline publication because we consider the content too narrow or too discipline-centered to warrant publication in our interdisciplinary journal.

2. Dealing fairly with a revised manuscript. Sometimes, we ask an author to make revisions, attending to the comments of the external reviewers, and in revising, the author slavishly follows every reviewer comment, and comes up with a revision that bears little connection to the original, and we need to send it back through another review cycle. We need to improve our own editorial skills to help authors out here.

3. Dealing fairly with manuscripts that come to us from Africa. We regularly relax the submission formalities with such manuscripts, as many of our colleagues on the continent do not have access to up-to-date research materials and technologies. We do not, however, relax the content standards. Many manuscripts shine with detailed cases from close observation, and we and the external reviewers provide copious suggestions for revision, yet the authors simply do not have access to the requisite research materials. Several of our reviewers generously offer to photocopy and send to us copies of key citations, essays and/or data to forward along to authors. We gratefully accept.

\section{Does the ASR still need or want manu- scripts right now?}

Absolutely we do, and we need more of them; we encourage readers/scholars to think of publishing first in the ASR, before trying a disciplinary journal. We are an interdisciplinary journal, but that does not mean that we are uninterested in disciplinary material; only that the material should have an interdisciplinary appeal. Since we took over as editors, here's our score for these past two years:

A. On August 18, 1997, we inherited 48 mss. from former editor, Mark Delancey. Here's how we dealt with them: Accept: 3; Reject: 37; Revise and Resubmit: 7; Revise and Resubmit and now back out on review: 1

B. Since we became editors, we have received 162 manuscripts. Here's our decision statistics: Accept: 16; Reject: 82; Out on review: 21; Revise and Resubmit: 18; Incomplete submission (awaiting missing elements): 15; With- drawn by author: 6; In process: 4 .

Want to submit a manuscript? Here's what to do:

1. Submit three copies that are typed double-spaced, in a 12 point font size (10 characters per inch). The text should not be longer than 25 pages, excluding references and notes.

2. Maps, tables, charts and other illustrations must be camera-ready.

3. Citations within the text should follow the author-date standard described in chapter 16 of the 14th edition of A Manual of Style (University of Chicago Press, 1993).

4. Complete bibliographic references to the citations should be provided at the end of the essay in a section entitled "References." The standard is page 648 of the aforementioned A Manual of Style. The only items that appear in the "References" section are those actually cited in the body of the text.

5. "Notes" should follow the References. They should be formatted according to the conventions of A Manual of Style, sections $15.35-15: 40$

6. Manuscripts will be sent to external peer reviewers; include a removable cover page giving essay title, author name and mailing address, fax number and e-mail address, if available; title should be repeated on the first page of text, but the author's name should appear only on the cover page.

7. Include an abstract of not more than 200 words.

8. Include a signed statement that the essay has not been published and is not currently under consideration by other journals. The ASR will only consider unpublished manuscripts.

Send manuscripts to: Editors, The African Studies Review, Department of Anthropology, University of Massachusetts, Amherst, MA 01003-4805.

N.B.: This set of requirements is listed in the inside cover of the ASR, from volume 41 onward.

\section{Can you assist the editors by reviewing} books and manuscripts?

Yes; please complete the form that follows on the next page, and mail it to us at the address above. If you completed such a form already and wish to revise what you indicated, or if you can't remember whether you filled in such a form or not, please fill it in anyway; what you submit will be either new or will replace what we now have for you.

\section{Ralph Faulkingham and Mitzi Goheen} ASR Editors 


\section{A S A 7 N E W S}

\section{Dear ASA Member:}

We want you to help us review books and manuscripts for the African Studies Review. Please circle all the descriptors that apply to you in the lists below, then tell us your address details, and mail the form back to us at: ASR, Department of An thropology, UMass, Amherst, MA 010034805 USA.

\begin{tabular}{|c|c|c|c|}
\hline Discipline: & democracy & theater & Guinea-Bissau \\
\hline Agricultural Sciences & demography & tourism & Ivory Coast \\
\hline Anthropology & development & transportation & Kenya \\
\hline Archaeology and Prehistory & entrepreneurship & & Lesotho \\
\hline Art & farming & Region(s): & Liberia \\
\hline Communications & fiction & Africa-general & Libya \\
\hline Economics & film & North & Madagascar \\
\hline Education & gender & South & Malawi \\
\hline Geosciences & globalization & East & Mali \\
\hline History & government/civil service & West & Mauritania \\
\hline International Relations & health, nutrition \& disease & Central & Morocco \\
\hline Journalism & human rights & Algeria & Mozambique \\
\hline Law/Legal Studies & international trade & Angola & Namibia \\
\hline Library Sciences & land tenure & Benin & Niger \\
\hline Linguistics & language & Botswana & Nigeria \\
\hline Literature & local/regional trade & Burkina Faso & Rwanda \\
\hline Management & media & Burundi & Senegal \\
\hline Medicine/Public Health & multilateral organizations & Cameroon & Sierra Leone \\
\hline Philosophy & music/dance & Central African Rep. & Somalia \\
\hline Political Science & natural resources & Chad & South Africa \\
\hline Religion & NGOs & Congo-Brazzaville & Sudan \\
\hline Sociology & pastoralism & Congo-Kinshasa & Swaziland \\
\hline Women's Studies & politics & Egypt & Tanzania \\
\hline & popular culture & Equatorial Guinea & Togo \\
\hline Topic: & pre-colonial & Eritrea & Tunisia \\
\hline agribusiness & post-colonial & Ethiopia & Uganda \\
\hline banking/finance & refugees & Gabon & Western Sahara \\
\hline civil society & religion/ritual & Gambia & Zambia \\
\hline colonial & rural/urban planning & Ghana & Zimbabwe \\
\hline conflict/war & slavery & Guinea & \\
\hline
\end{tabular}

First Name:

Last Name:

Address:

Telephone:

Fax:

E-mail:

From Eugenia Herbert, Book Review Editor for the African Studies Review:

Our book reviewers are chosen primarily from our reviewer database, but also through suggestions from other reviewers and specialists. To avoid possible conflict of interest, we have a general policy of not accepting unsolicited reviews. Also we do not normally print rebuttals to book reviews. Unfortunately, the ASR cannot review all the books generously sent to us by publishers. Either we lack the space to include reviews in a timely way, or we consider there is insufficient fit, given our purview. Thus, under "Books Received" we list those that have come in but have not been sent out for review, so that at least publication information will be available to ASR readers.

We are very grateful to the many scholars who have answered our request for reviews. We especially appreciate their patience in the face of long delays. Now that we are catching up with our production schedule, may we request that those with outstanding book reviews please get them in as soon as possible? 